\title{
Study on Technical Standards of Reinforced Concrete Structures with Long Service Life when Using Blended Cement and Finishing Materials
}

\author{
Tadatsugu Kage $^{1}$, Hiroyuki Tanano ${ }^{1}$, Naoko Tsuchiya ${ }^{2}$ and Hiroshi Jinnai ${ }^{3}$ \\ ${ }^{1}$ Dept. of Department of Building Materials and Components, Building Research Institute, 1 \\ Tachihara, Tsukuba-c., Ibaraki-pref., Japan, kage@kenken.go.jp \\ ${ }^{2}$ Building Dept., National Institute for Land and Infrastructure Management, Ministry of Land, \\ Infrastructure and Transport, 1 Tachihara, Tsukuba-c., Ibaraki-pref., Japan, tuchiya-n92ta@mlit.go.jp \\ ${ }^{3}$ Dept. of Architecture, Faculty of Engineering, Tokyo Polytechnic University, 1583 Iiyama, Atsugi- \\ c., Kanagawa-pref., Japan, jinnai@arch.t-kougei.ac.jp
}

\begin{abstract}
It is very important to improve and secure durability of reinforced concrete $(R C)$ building and housing, in order to extend the service life of it. In this study, these were studied experimentally that the contribution ratio of blended cement to the carbonation resistance of concrete when a part of OPC replaced to FA or BFS much more were used for concrete, and the effect of carbonation suppression required for an effective finishing materials when these were applied for concrete surface. As a result, we were able to obtain the knowledge that the contribution ratio to the carbonation resistance of concrete using blended cement with different mixture replacement ratio, and the effect of carbonation suppression required for 4 types of finishing materials and its specifications, from the viewpoint of securing durability and extending the service life of RC structures. Therefore, these were considered to be able to sufficiently contribute to the review of the evaluation method or technical standards concerning about the durability of RC structures prescribed in "Housing Quality Assurance Act" in Japan.
\end{abstract}

Keywords: Blended Cement, Finishing Materials, Water-Cement Ratio, Depth (thickness) of Concrete Cover, Resistance or Suppression of Carbonation.

\section{Introduction}

It is very important to improve and secure durability of reinforced concrete (RC) building and housing, in order to extend the service life of it. In Japan, the technical standards concerning about the durability of RC structures and quality of concrete are prescribed in "Housing Quality Assurance Act". In the notification No.1374 shown in Table 1 related to this laws, the subjects of "phenomenon of deterioration" are the rust of rebar caused by carbonation of concrete. This table means a necessary measures have been taken to extend the period of large-scale repair work is not required up to 3 generations (generally 75-90 years) under the general conditions of environment and maintenance that are normally assumed. And, as the evaluation standards of "reduction of deterioration" for concrete, the relationship between water-cement ratio (W/C) and depth (thickness) of concrete cover is prescribed depending on the required durability (carbonation resistance) of concrete. This is because the thickness of concrete cover in the RC structures directly affects the corrosion of the rebar due to the carbonation of the cover concrete. Therefore, in order to improve the durability performance and to extend service life of RC structures, it is necessary to increase the cover thickness or reduce the $\mathrm{W} / \mathrm{C}$ of concrete. 
In addition, this technical standard is specified assuming concrete using ordinary portland cement (OPC), and when using fly ash (FA) or ground granulated blast-furnace slag (BFS) for concrete, the mass of cement for calculating W/C must be excluding all (100\%) of FA in this certification standards. Also, the mass of cement for calculating W/C must be excluding $30 \%$ of BFS, i.e. the "contribution ratio of carbonation resistance" of FA and BFS are defined as 0 and 0.7 . This concept is determined in consideration of the contribution ratio of the mixture in blended cement to the carbonation resistance of concrete. This concept is determined by the replacement ratio of FA of about $15 \%$ and BFS of about $45 \%$, which are equivalent to "Type B" in Japanese Industrial Standards (JIS), also based on many previous research and survey such as guidelines of Architectural Institute of Japan (AIJ).

Therefore, in case of using the blended cement and using FA or BFS much more for concrete, it is necessary to reduce the $\mathrm{W} / \mathrm{C}$ of concrete much more, or to use the effective finishing material for durability, for examples, tiling, mortar coating, external insulation methods, etc. Table 1 shows that an effective finishing material for durability, and W/C of 5\% are equivalent to a concrete cover of $1 \mathrm{~cm}(10 \mathrm{~mm})$. However, tiling, mortar coating, external insulation methods, and the like are exemplified as effective finishing material for durability, but required performance is not shown.

In this study, these were studied experimentally that the contribution ratio of blended cement to the carbonation resistance of concrete when a part of OPC replaced to FA or BFS much more were used for concrete, and the effect of carbonation suppression required for an effective finishing materials when these were applied for concrete-surface. This study might be so useful to get the technical environmental load in the

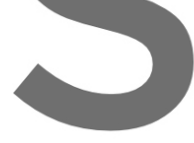
Table 1. Certification
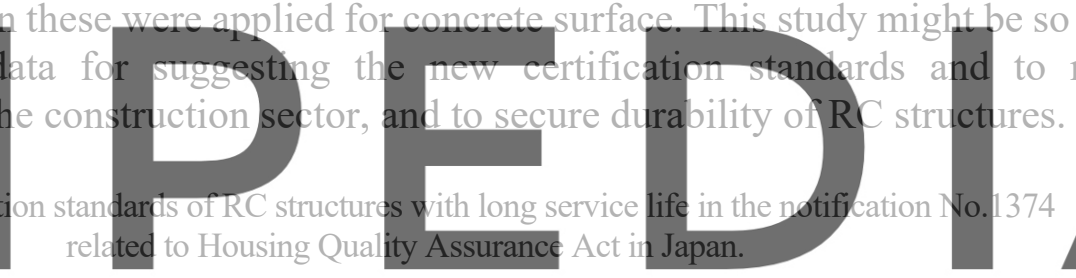

Part or members of RC structures

Register for free at https//wwaks scipediaicomalito dowmbolad the version withouththe watermark

\begin{tabular}{lllll} 
not contacts $\begin{array}{l}\text { directly with the } \\
\text { ground }\end{array}$ & slab of floors & outside* & $3 \mathrm{~cm}$ & $4 \mathrm{~cm}$ \\
\cline { 2 - 4 } & bearing wails, coiumns, beams & inside & $3 \mathrm{~cm}$ & $4 \mathrm{~cm}$ \\
\cline { 2 - 4 } $\begin{array}{l}\text { contacts directly } \\
\text { with the ground }\end{array}$ & $\begin{array}{l}\text { walls, columns, slab of floors, beams, } \\
\text { rising part of continuous foundation }\end{array}$ & $4 \mathrm{~cm}$ & $5 \mathrm{~cm}$ \\
\cline { 2 - 4 } & $\begin{array}{l}\text { foundation (except the rising part of continuous } \\
\text { foundation, and leveling concrete) }\end{array}$ & $6 \mathrm{~cm}$ & $5 \mathrm{~cm}$ \\
\hline
\end{tabular}

Note *: It could be reduced by $1 \mathrm{~cm}(10 \mathrm{~mm})$ on the outside, by using an effective finishing material for durability (ex: tiling, mortar coating, external insulation methods, etc.)

\section{Carbonation Resistance of Concrete Using Blended Cement}

An accelerated carbonation test was performed on specimens with changed water-binder ratio (W/B), the type and replacement ratio of mixture, and the ratio of each mixture contributing to the carbonation resistance was clarified experimentally. The goal is to provide useful and technical data for durability design of RC structures using blended cement. 


\subsection{Outline of Experiment}

Table 2 shows the experimental factors and levels and their combinations. The W/B were 30, $40,50,60 \%$, and the mixture replacement ratio is selected from 2 kinds of 15 and $25 \%$ for FA and 1 to 3 kinds selected for BFS of 30,50 , and $70 \%$. It was set as the combination. In addition, when OPC was used, specimens with $\mathrm{W} / \mathrm{B} 80 \%$ and $100 \%$ were prepared in order to confirm the compressive strength and carbonation resistance of the specimen with a small amount of cement per unit volume of concrete. In addition, in order to ascertain the carbonation resistance of specimens using commercially available portland blast-furnace slag cement (Type B), W/B50\% specimens (with a replacement ratio of 40-45\%) were prepared and subjected to the same tests. The accelerated carbonation test conformed to JIS A 1153 (Method of accelerated carbonation test for concrete). The pre-curing was performed under standard curing until the age of 28 days, and then in-air curing at $20^{\circ} \mathrm{C}, 60 \%$ R.H. until the age of 56 days.

Table 2. Experimental factors and levels.

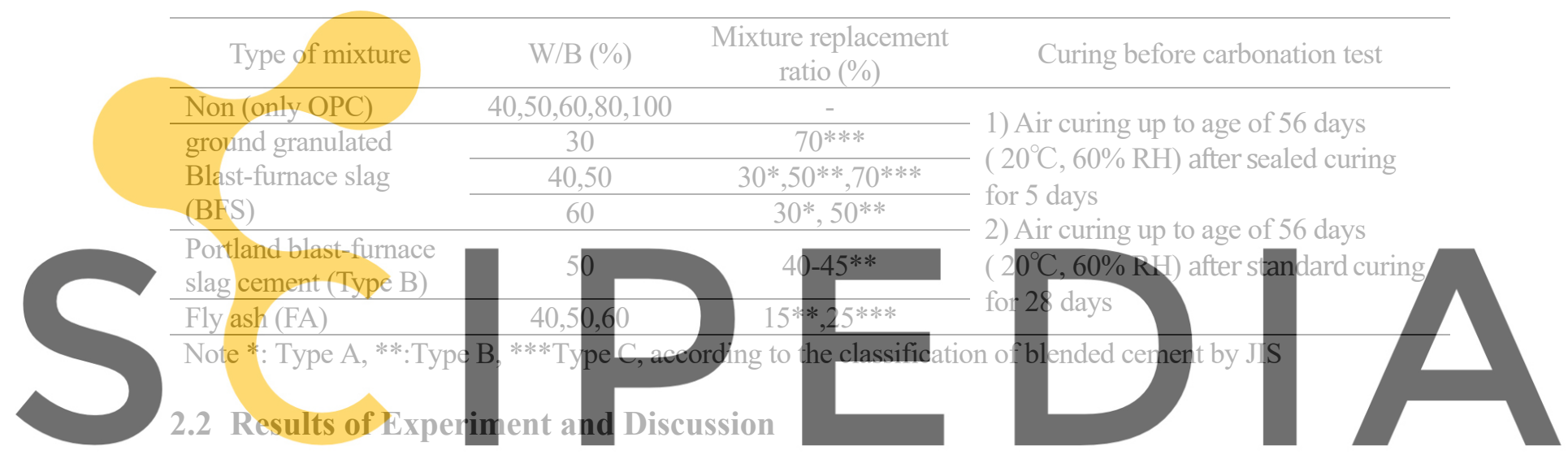

Figure 1 shows the relationship between the compressive strength and the carbonation rate

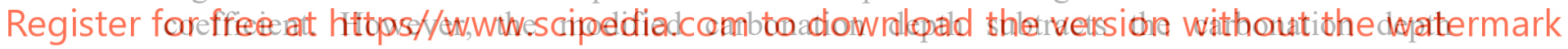
immediately before the start of the test (age of 0 week). The figure shows that the standard curing 28days compressive strength and the carbonation rate coefficient have a strong correlation, and the carbonation rate coefficient tends to decrease as the standard curing 28days compressive strength increases, regardless of the type of mixture and the replacement ratio.

Figure 2 shows the relationship between W/B and the carbonation rate coefficient, in case of using BFS. There was a strong linear correlation between W/B and the carbonation rate coefficient, which was similar when FA was used. Here, the ratio that the mixture contributes to carbonation resistance as a replacement of OPC was defined as "contribution ratio of carbonation resistance $(\alpha)$ ". Using the contribution ratio $\alpha$, the amount of binder that contributes to carbonation resistance was determined as equation (1). In this equation, the "mixture" indicates mixtures (FA or BFS).

$$
\text { Amount of Binder }=\text { Amount of OPC }+\alpha \times \text { Amount of mixture }
$$

Figure 3 shows a trial calculation of the carbonation rate coefficient when $\alpha$ is changed by 0.2 from 0 to 1.0 , in case of $\mathrm{BFS} 50 \%$. It was assumed that the ratio of mixture that could contribute to carbonation resistance as a replacement of cement could be estimated by back- 
calculating $\alpha$ at the intersection where the trial calculation results of each $\alpha$ and the line of OPC $(\mathrm{N}$, in Fig) intersect. Using this estimation method, the contribution ratio $(\alpha)$ of the carbonation resistance according to the mixture replacement ratio of FA and BFS were calculated and shown in Table 3. For $\alpha$ of fly ash, FA15 was 0.07 to 0.42 , FA25 was 0 to 0.17 . For $\alpha$ of ground granulated blast-furnace slag, BFS30 was 1.04 to 1.07 , BFS50 was 0.83 to 0.84 , BFS70 was 0.45 to 0.69 . Among the mixtures, BFS had a higher contribution ratio of the carbonation than FA, and the greater the replacement ratio of mixture, the smaller the contribution ratio.

As the results, these were obtained that the ratio excluding BFS from the mass of cement for calculating W/C may be $0 \%$ for Type A, $20 \%$ for Type B and $30 \%$ to $60 \%$ for Type C. Also, in case of FA, it may be $60 \%$ to $100 \%$ for Type B and $90 \%$ to $100 \%$ for Type C. Therefore, it was found that the current standard (Table 1) could be mitigation in some cases.
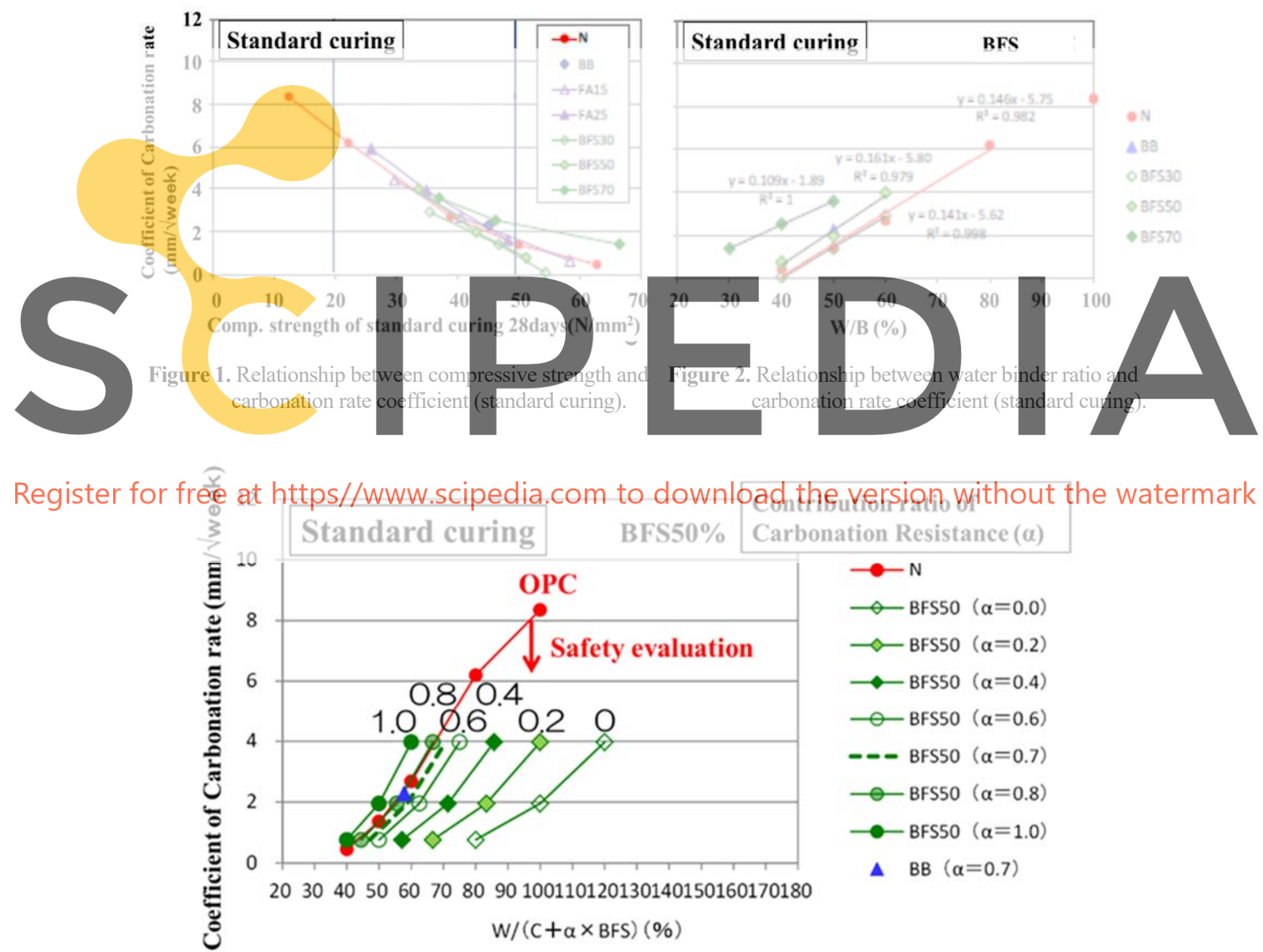

Figure 3. Calculation results of carbonation rate coefficient changing contribution ratio $\alpha$. 
Tadatsugu Kage, Hiroyuki Tanano, Naoko Tsuchiya and Hiroshi Jinnai

Table 3. Calculation results of Contribution ratio for Carbonation Resistance.

\begin{tabular}{|c|c|c|c|c|c|c|}
\hline \multirow{3}{*}{ Binder } & \multirow{3}{*}{$\begin{array}{c}\text { Mixture } \\
\text { replacement } \\
\text { ratio }(\%)\end{array}$} & \multirow{3}{*}{$\begin{array}{c}\text { Blended Cement } \\
\text { (JIS) }\end{array}$} & \multirow{2}{*}{\multicolumn{4}{|c|}{$\begin{array}{c}\text { Contribution ratio of Carbonation Resistance } \\
\text { W/B }(\%)\end{array}$}} \\
\hline & & & & & & \\
\hline & & & 30 & 40 & 50 & 60 \\
\hline \multirow{2}{*}{$\begin{array}{l}\text { OPC(N) } \\
+ \text { FA }\end{array}$} & 15 & Type B & - & 0.42 & 0.21 & 0.07 \\
\hline & 20 & Type C & - & 0.17 & 0.07 & 0.00 \\
\hline \multirow{3}{*}{$\begin{array}{l}\mathrm{OPC}(\mathrm{N}) \\
+\mathrm{BFS}\end{array}$} & 30 & Type A & - & 1.04 & 1.06 & 1.07 \\
\hline & 50 & Type B & - & 0.84 & 0.84 & 0.83 \\
\hline & 70 & Type C & 0.45 & 0.59 & 0.69 & - \\
\hline
\end{tabular}

\section{Suppression Effect of Finishing Materials on Carbonation of Concrete}

In RC structures, finishing materials that can suppress the intrusion of carbon dioxide, which causes carbonation, are often applied to the concrete surface. It is possible to use the effect of carbonation suppression of finishing materials. However, there were few experimental data that confirmed it such as tiling, mortar coating, and external insulation methods, and it was not clear how to select finishing materials that can be considered equivalent effect. Here, confirmation of the effect of suppression the carbonation of concrete of 4 types of finishing materials, which were tile, mortar, external insulation and coating materials for textured finishes, and the evaluation method of the suppression effect, were examined.
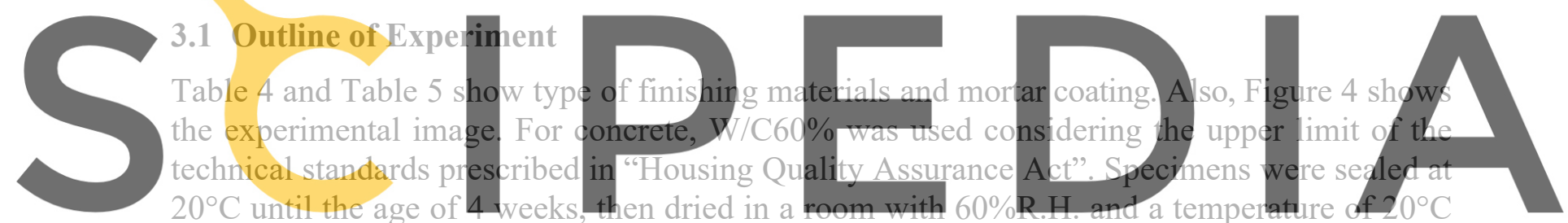

until the age of 8 weeks, and then mortar was applied to one side of the mold surface. Thus, a

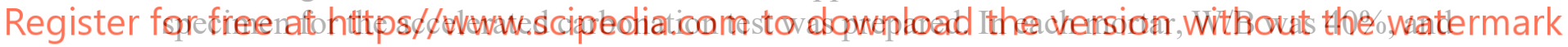
the binder: fine aggregate $=1: 2.5$ (mass ratio). The binder used for mortar was OPC, and highearly-strength portland cement (HPC), which could be expected to develop early strength, and silica fume (SF), which could be expected to be densify the concrete, $5 \%$ (mass ratio) of the binder was replaced. The type of aggregate was based on natural sand, and perlite artificial lightweight aggregate (standard weight $0.17 \mathrm{~kg} / \mathrm{L}$ ) was also used.

The mortar coating was applied to concrete specimens, with the variable factors being the type of binder and aggregate, the amount of polymer (main component: ethylene vinyl acetate copolymer emulsion), the thickness of mortar and the curing method after mortar coating. The effect of carbonation suppression of mortar coating was confirmed.

The amount of polymer mixed in the mortar is based on $\mathrm{B} \times 3 \%$ as a general value in finished mortar, and $\mathrm{B} \times 6 \%$ with an increased amount of polymer was also examined. The thickness of mortar applied to the specimen was basically $10 \mathrm{~mm}$, and as shown in the Table 5, the mortar thickness was varied within the range of 5 to $30 \mathrm{~mm}$. The method of curing the specimens after mortar coating was based on air curing in a room at about $20^{\circ} \mathrm{C}$, and examination was also made on those that were cured for 2 or 7 days after coating. The accelerated carbonation test started at concrete curing age of 12 weeks, in accordance with JIS A 1153. Also, the carbonation depth of concrete was measured at test age of 8, 13, 26 and 52 weeks. 
Table 4. Type of Finishing Materials.

\begin{tabular}{|c|c|}
\hline Type of finishing materials & Materials and symbols \\
\hline Non & Concrete $(\mathrm{C} 1)$ \\
\hline Tile & Water absorption type 1(T1, T2(with M8), T3)、 type 2(T4, T5(with M8)) \\
\hline Mortar & $\begin{array}{l}\text { Primer }(\mathrm{C}-1(\mathrm{t}=1 \mathrm{~mm}(\mathrm{M} 1, \mathrm{M} 2)), \mathrm{C}-2(\mathrm{t}=2 \mathrm{~mm}(\mathrm{M} 3, \mathrm{M} 4))) \text {, } \\
\text { Primer(CM-1 }(\mathrm{t}=10 \mathrm{~mm}(\mathrm{M} 5, \mathrm{M} 6)), \mathrm{CM}-2(\mathrm{t}=10 \mathrm{~mm}, \mathrm{M} 7, \mathrm{M} 8))) \\
\text { On-site mixing mortar(t=10mm,M9), }(\mathrm{t}=15 \mathrm{~mm}, \mathrm{M} 10)\end{array}$ \\
\hline External insulation & $\begin{array}{l}\text { Polystyrene type } 4(\mathrm{t}=30 \mathrm{~mm}, \mathrm{IN} 1, \mathrm{IN} 2) \text {, Polystyrene type } 3(\mathrm{t}=30 \mathrm{~mm}, \mathrm{IN} 3) \text {, } \\
\text { Urethane foam typeA22(t=30mm, IN4) }\end{array}$ \\
\hline $\begin{array}{l}\text { Coating materials } \\
\text { for textured finishes }\end{array}$ & $\begin{array}{l}\text { Multi-layer coating materials for textured finishes(CM1,CM2), } \\
\text { Coating materials for thick textured finishes(CM3,CM4), } \\
\text { Coating materials for thin textured finishes(CM5) }\end{array}$ \\
\hline
\end{tabular}

Table 5. Type of Mortar Coating.

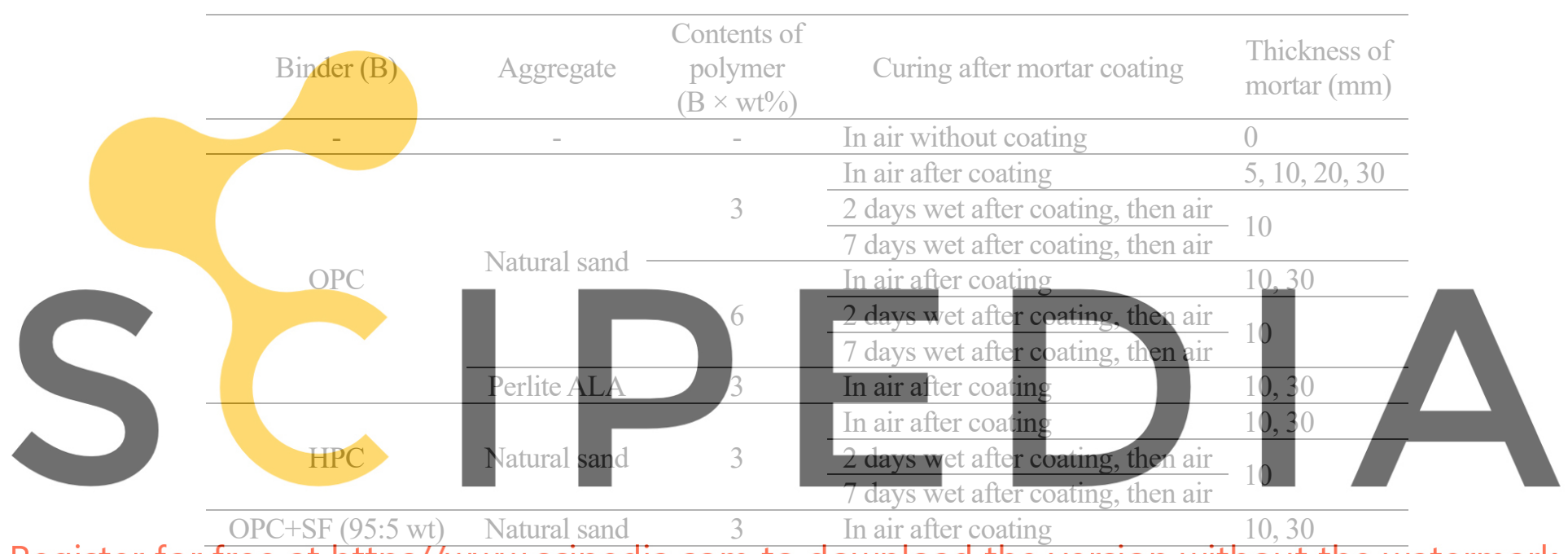

Register for free at https//www.scipedia.com to download the version without the watermark

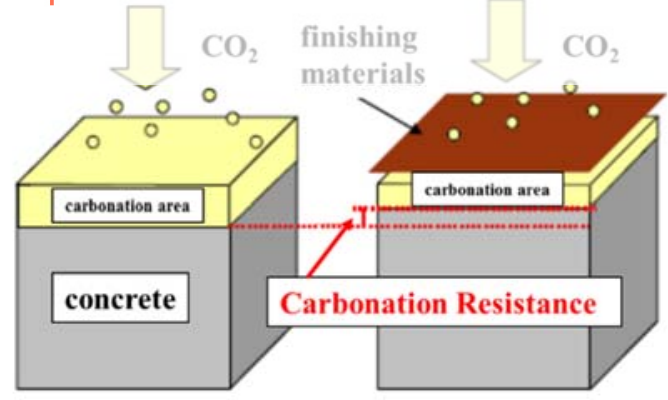

Figure 4. Outline of experiment.

\subsection{Results of Experiment and Discussion}

Figure 5 shows the carbonation depth of each specimen at the test age of 52 weeks. In this figure, the carbonation depth of the specimen that was not finished was also shown, and the value when the carbonation depth was $10 \mathrm{~mm}$ smaller than that was shown by the dotted line. As a result, it was found that the finishing material other than mortar has an effect of carbonation suppression of more than $10 \mathrm{~mm}$ compared to the specimen $\mathrm{C} 1$ (exposed concrete). 

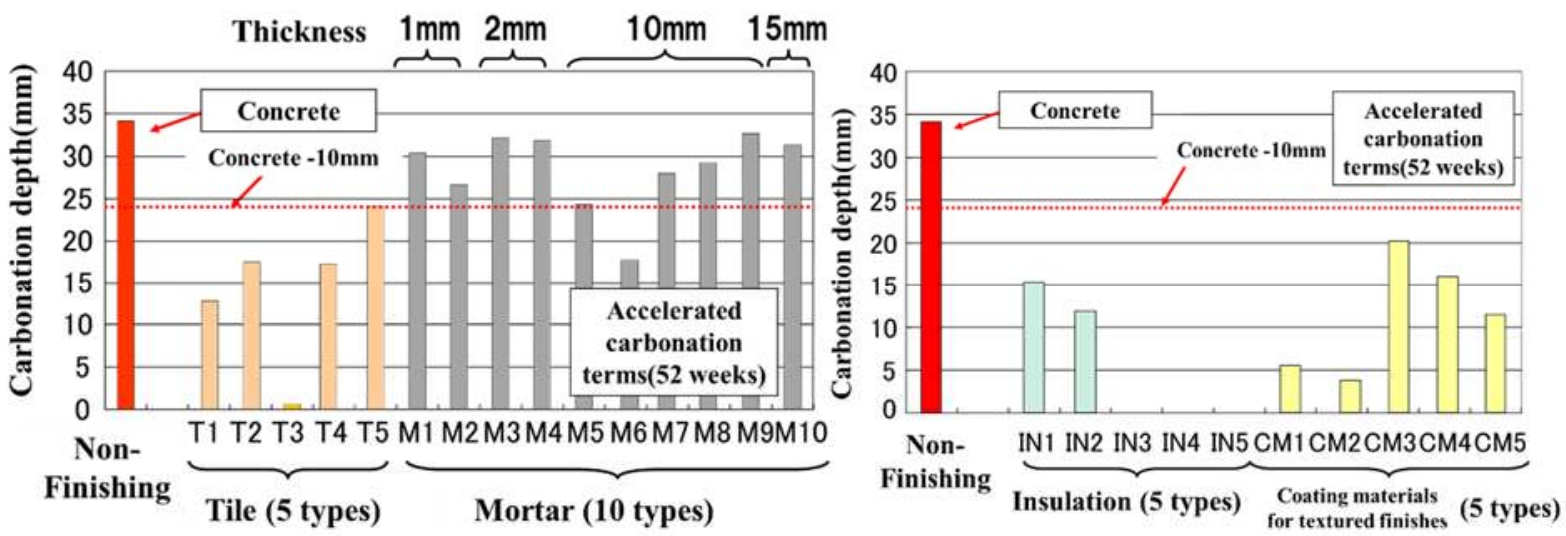

Figure 5. Carbonation depth of concrete with 4 types of finishing materials.
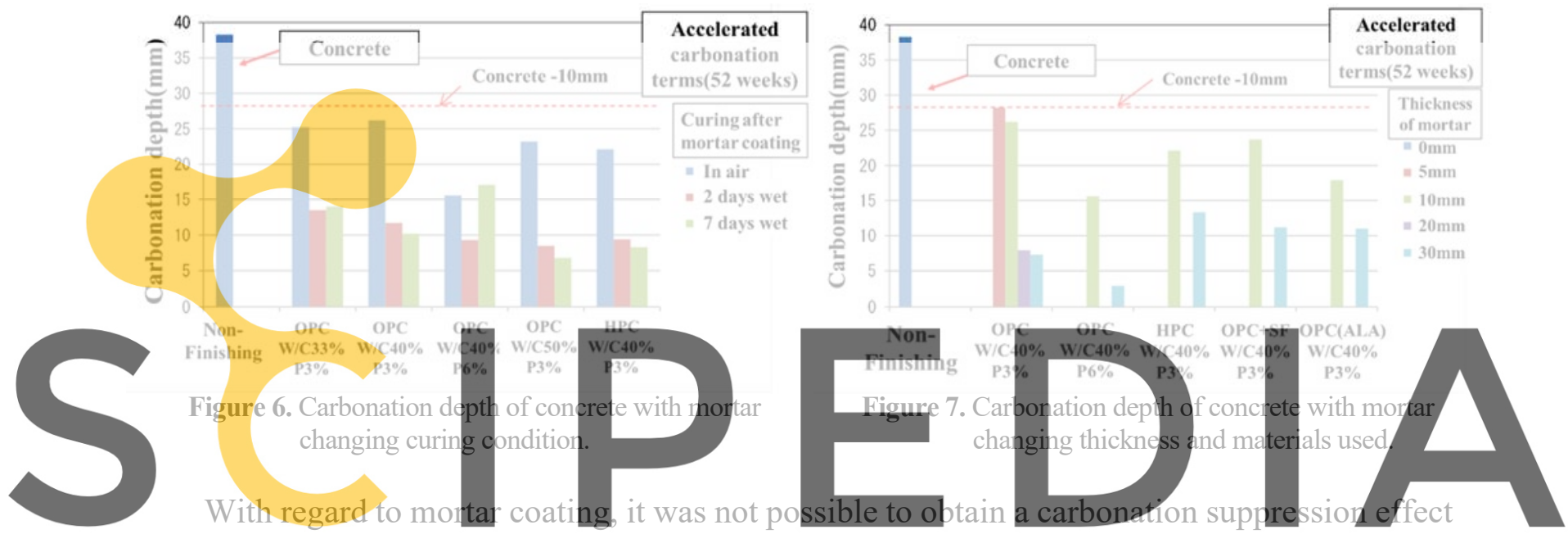

of $10 \mathrm{~mm}$ or more with a primer of 1.0 to $2.0 \mathrm{~mm}$, and an equivalent thickness of at least about

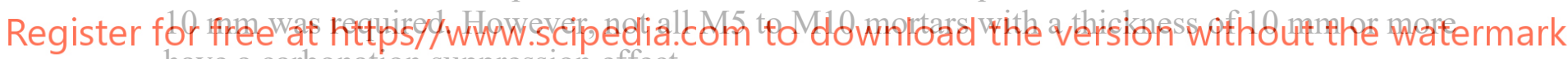
have a carbonation suppression effect.

Figure 6 shows the test results of the carbonation depth of concrete with a mortar thickness of $10 \mathrm{~mm}$, at the test age of 52 weeks. The compressive strength of the mortar at the age of 28 days was greatly improved by the wet curing after mortar coating, and the carbonation suppression effect by the mortar was also greatly improved. In addition, in this experiment, it was suggested that by increasing the amount of polymer mixed in the mortar, the carbonation suppression effect equivalent to the case of wet curing can be obtained even if it was cured in the air. Figure 7 shows the test results of the carbonation depth of concrete cured in air after mortar coating at the test age of 52 weeks. As the thickness of mortar increased, the effect of suppressing carbonation increased. In this experiment, if the mortar thickness was $10 \mathrm{~mm}$ or more, the effect of suppressing carbonation was obtained equivalent $10 \mathrm{~mm}$ or more compared to the specimen $\mathrm{C} 1$ (exposed concrete) even if wet curing was performed. For mortar with HPC as the binder or mortar in which part of the binder was replaced with silica fume, the test results at test age of 13 weeks tended to slightly improve the carbonation suppression effect of mortar. However, the same trend was not clearly confirmed at the test age of 52 weeks. For the mortar using lightweight aggregate, the compressive strength was as low as about $40 \%$ when using natural sand, but the carbonation suppression effect was equivalent to that of mortar using 
natural sand.

As the results, it was confirmed that the 4 types of finishing materials, which were tiling, mortar coating, and external insulation method and a finishing coating material, had the same carbonation suppression effect as the concrete cover thickness of $10 \mathrm{~mm}$, i.e. $\mathrm{W} / \mathrm{C} 5 \%$. In addition, these were obtained that the effect of carbonation suppression of mortar coating could be improved by initial curing, the amount of polymer increase and the mortar coating (thick coating) of about $30 \mathrm{~mm}$.

\section{Conclusions}

We were able to obtain the knowledge that the contribution ratio of blended cement to the carbonation resistance of concrete when a part of OPC replaced to FA or BFS much more were used for concrete, and the effect of carbonation suppression required for an effective finishing materials and its specifications when these were applied for concrete surface, from the viewpoint of securing durability of reinforced building and housing.

The results obtained were as follows:

- The ratio excluding FA from the mass of cement for calculating W/C may be $60 \%$ to $100 \%$ for Type B and $90 \%$ to $100 \%$ for Type C. Also, in case of BFS, it may be $0 \%$ for Type A, 20\% for Type B and 30\% to $60 \%$ for Type C.

The 4 types of finishing materials, which were tiling, mortar coating, and external insulation method and a finishing coating material, had the same carbonation

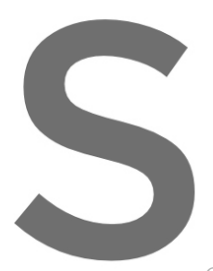
suppression effect as the concrete cover thickness of 1
The effect of carbonation suppression of mortar coati
curing, the amount of polymer ingrease and the mortar
$30 \mathrm{~mm}$.
he results, these were considered to be able to sufficient

As the results, these were considered to be able to sufficiently contribute to the review of the
evaluation method or technical standards concerning about the durability of RC buildings and housing prescribed in "Housing Quality Assurance Act" in Japan.

Register for free at https//www.scipedia.com to download the version without the watermark Acknowledgements

We would like to thank all those who have contributed to this experimental research.

\section{ORCID}

Tadatsugu Kage: http://orcid.org/0000-0002-0767-2622

Hiroyuki Tanano: http://orcid.org/0000-0003-0165-237X

Naoko Tsuchiya: http://orcid.org/0000-0002-9500-9811

Hiroshi Jinnai: http://orcid.org/0000-0003-0810-7999

\section{References}

Architectural Institute of Japan (2007). Recommendation for Practice of Concrete Building with Fly Ash..

Architectural Institute of Japan (2017). Recommendation for Design and Practice of Reinforced Concrete Building with Portland Blast-Furnace Slag Cement or Ground Granulated Blast-Furnace Slag.

Notification No.1374, Housing Quality Assurance Act, JAPAN

Toshinori, O. et al. (2014-2016). Durability Performance of Blended Cement Concrete (part 1-7), Summaries of Technical Papers of Annual Meeting, Architectural Institute of JAPAN.

Yoshihiro,M. et al. (2011-2013). Basic Study on Carbonation Suppressive Effect of Finish Materials for Concrete (part 1-8), Summaries of Technical Papers of Annual Meeting, Architectural Institute of JAPAN. 